\title{
The Influence of Adolescent Problem Behaviors on Life Satisfaction: Parent-Child Subsystem Qualities as Mediators
}

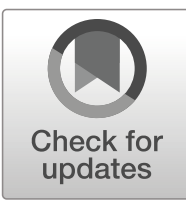

\author{
Xiaoqin Zhu ${ }^{1} \cdot$ Daniel T. L. Shek ${ }^{1}$
}

Accepted: 13 January 2020 / Published online: 18 January 2020

(C) The Author(s) 2020

\begin{abstract}
Research studies showed that adolescent problem behaviors were negatively associated with their life satisfaction. However, the negative impact of problem behaviors on life satisfaction has not been sufficiently researched using longitudinal design and the potential mechanisms have not been well examined. The present study attempted to investigate how early adolescents' externalizing and internalizing behaviors affect their life satisfaction (LS) as well as the mediating effects of parent-child subsystem qualities. Based on a sample of 2669 Chinese adolescents in Hong Kong who were followed up for three years, the present study found that both externalizing and internalizing behavior led to a decrease in LS among adolescents over time. While parental behavioral control and parent-child relational quality mediated the effects of externalizing behavior, parental factors did not mediate the effects of internalizing behavior. More specifically, parents tended to respond to children's externalizing behavior by reducing parental involvement and warmth, which subsequently resulted in lower LS of adolescents. The findings imply that it is necessary to promote adolescent LS by reducing their problem behaviors. Moreover, parents should develop effective ways to enhance their understanding of children's emotional and behavioral difficulties.
\end{abstract}

Keywords Longitudinal design · Chinese adolescents · Well-being · Externalizing behavior - Internalizing behavior

\section{Introduction}

During the past several decades, the scope of youth research has expanded from the focus on psychopathology and its contributors (i.e., deficit perspective) to emphasis of the bright side of adolescents such as strengths, assets, and potential (i.e., positive

Daniel T. L. Shek

daniel.shek@polyu.edu.hk

1 Department of Applied Social Sciences, The Hong Kong Polytechnic University, Kowloon, Hong Kong, People's Republic of China 
psychology approach; Seligman and Csikszentmihalyi 2014). Based on the positive psychology perspective, multiple strengths have been highlighted in the extant literature, such as hope, resilience, and subjective well-being (Diener et al. 2012). Particularly, scholars contended that the investigation of youth well-being in addition to traditional psychopathological symptoms is essential to fully understand young people's psychosocial development and healthy functioning (Huppert 2009). For example, inclusion of subjective well-being (e.g., happiness and positive affect) to psychopathological indicators (e.g., depression and other illness) helps portray a full picture of student mental health and accounted for a considerably larger amount of individual variances in developmental outcomes (Huebner et al. 2014).

Life satisfaction (LS), known as the cognitive element of subjective well-being, has drawn the most research attention in positive psychology (Huebner et al. 2012). Defined as one's general appraisal of the overall quality of life, LS represents a conscious evaluation process that allows one to assess the extent to which his or her life meets the expectation (Pavot and Diener 1993). LS is an important psychological strength that fosters adaptive development and optimal functioning among children and adolescents. For example, in Proctor, Linley, and Maltby's (2009) review, higher LS among children and adolescents was closely linked with their higher engagement in school, stronger motivation, better academic performance, and more positive selfconcept. Similar findings were repeatedly reported in recent studies (Heffner and Antaramian 2016; Marques et al. 2015). Furthermore, students with higher LS received greater support from parents, teachers, and peers, and demonstrated fewer behavioral problems (Danielsen et al. 2009; Suldo et al. 2008).

In short, LS plays an important role in children's overall adaptations. Unfortunately, research findings suggest that LS decreases since early adolescence. Such an observation has been reported in different countries such as the United States (Proctor et al. 2009), South Korea (Park 2005), and Hong Kong (Shek and Liang 2018). In view of such a declining trend in LS and the possible negative consequences of lower LS among adolescents, it is essential to delineate the determinants of variations in adolescent LS. Among different factors, problem behavior has been commonly regarded as a major correlate of lower LS. A number of crosssectional studies have shown that low LS was related to adolescents' problem behaviors (Flaspohler et al. 2009; Bartels et al. 2013), including externalizing (i.e., outward-oriented problems such as violence and delinquency) and internalizing behavior (i.e., inward-oriented problems such as depression and self-harm). However, such correlational evidence cannot tell causality. Thus, there is a need to further investigate whether adolescent maladaptive behavior will damage their LS using longitudinal data. Besides, possible mechanisms underlying the potential impacts of maladaptive behavior on LS should be explored.

\subsection{Negative Impacts of Maladaptive Behavior on LS}

Previous research has demonstrated negative associations between LS and adolescent externalizing and internalizing problems, such as aggressive behaviors (Schei et al. 2016), Internet addiction (Lachmann et al. 2016), substance abuse (Desousa et al. 2007), and depression as well as anxiety (Bartels et al. 2013). Some studies considered LS as a precursor of problem behaviors (Sun and Shek 2010, 2013). It is argued that adolescents who felt dissatisfied with their life might deal with life stress and adversities in maladaptive ways, such as engaging in risky behaviors, being addicted to Internet, or committing self-harm or 
even suicidal attempts (Sun and Shek 2010). However, it is also possible that adolescent maladaptive behaviors are antecedents of lower LS. Theoretically, the negative emotions attached to and the maladaptive nature of adolescent problem behaviors may narrow adolescents' cognitive and behavioral repertoires, which subsequently lead to a downward spiral of their negative cognitions and emotions, including decreased LS (Fredrickson 2001; Lyons et al. 2014).

A handful of research on the potential negative impact of adolescent maladaptive behavior on their LS was conducted within the framework of Evans' (1994) biosocialcognitive model, which was proposed to explain variations in LS. The model proposed that individual personality and environmental factors such as stress events are remote predictors of LS while individual social behavior (e.g., internalizing and externalizing behavior), affect, ability (e.g., learning skills), and social support are four proximal antecedents, which also serve as behavioral and social mediators between those remote predictors and LS. Several findings supported the paths incorporated in this integrative model. For instance, social and behavioral factors such as coping strategies, externalizing, and internalizing behavior mediated the relations between one's personality and LS (Lyons et al. 2013; Fogle et al. 2002).

Some of the above-mentioned findings supported the negative impacts of adolescent problem behaviors on their LS. For instance, Lyons et al. (2013) observed that both internalizing and externalizing behavior among early adolescents significantly predicted their lower levels of LS over two years. Some longitudinal findings also pointed out that problem behaviors during adolescence exerted long-term negative influences on one's LS, which continued into adulthood. For example, Bogart, Collins, Ellickson, and Klein (2007) reported that consumption of some forms of substance such as cigarettes and hard drugs in late adolescence was significantly associated with lower LS in early adulthood.

Despite the above-mentioned supportive findings for the negative impacts of adolescent problem behaviors on their LS, empirical research addressing this issue among early adolescents has been sparse. Furthermore, inconsistent findings also exist. For example, Lyons, Otis, Huebner, and Hills (2014) failed to identify any significant longitudinal predictive effect of externalizing or internalizing behavior on early adolescents' LS over six months. In view of the inadequate empirical research as well as equivocal findings, there is a need to further determine the causal effect of problem behaviors on LS among adolescents. This is especially important for early adolescents because of the well-documented decline in LS and increase in maladaptive behaviors during early adolescence (Shek and Lin 2016; Patel et al. 2007). Furthermore, Lyons et al. (2013) suggested self-reported externalizing behaviors might be more stable in comparison to internalizing behaviors, thus exerted more persistent impacts on LS. As such, there is also a need to further clarify the possible differential contributions of externalizing versus internalizing behaviors to the development of LS. Finally, mechanisms underlying the influence of maladaptive behavior on LS remain unknown. One possibility is that parents will respond to their child's problem behaviors in certain ways, which subsequently affect the child's LS. However, no empirical research has been carried out to examine this in the scientific literature.

\subsection{Mediating Effects of Parental Factors}

Socialization perspectives regard parental characteristics (e.g., parenting and parentchild relationship) as essential factors that shape children's development including the 
trajectory of maladaptive behavior (Steinberg 2001; Pinquart 2017). Meanwhile, there are other theoretical views suggest that behaviors of the child also affect the parents' subsequent parenting behaviors. For example, Bell (1977) proposed that parents increase controlling behaviors to keep the child's behavior within a tolerable range. Other scholars suggested that the child's antisocial behavior can reinforce his or her parents' dysfunctional discipline practices (Reid et al. 2002; Patterson 1982). It is reasonable that parents may change their parenting strategies after they notice their child's maladaptive acts. For example, the child's misbehavior could result in parents' harsher control and punishment. Alternatively, parents may raise their tolerance level and become less involved in socialization processes.

Empirical findings have revealed significant associations between the child's problem behavior and subsequent parental behavior. For example, Rogers, Buchanan, and Winchell (2003) reported that the child's internalizing problems lead to higher parental psychological control. Similarly, adolescent delinquency was found to result in poor parental attachment as well as less parental involvement (Gault-Sherman 2012). In addition, a higher level of antisocial behavior among early adolescents aged at 10 predicted less parental knowledge (an indicator of parental behavioral control) over two years (Wertz et al. 2016). In another recent study which followed up a sample of early adolescents in Taiwan for one year (Ko et al. 2015), it was found that adolescents with Internet addiction experienced more rapid decrease in family function when compared to non-addicted peers. Most importantly, in Pinquart's (2017) meta-analysis study, adolescent externalizing problems significantly predicted an increase in psychological and harsh control as well as declines in behavioral control, parental warmth, and authoritative parenting.

While it is very likely that parents adjust parenting practice due to the child's problem behaviors, parenting factors, in turn will affect the child's evaluation of his or her quality of life. In fact, parenting has long been recognized as important for the development of adolescent LS (Proctor et al. 2009). For instance, adolescents, whose parents showed authoritative or permissive parenting characterized by support, responsiveness, consistent regulation, and clear expectations, tended to have higher levels of LS than other adolescent peers with authoritarian parents who exerted harsh control but low responsiveness (Raboteg-Saric and Sakic 2014). Among Chinese adolescents, their parents' positive parenting practices, such as concern, support, and involvement, predicted higher levels of adolescents' LS, both concurrently and longitudinally (Chen 2014; Leung and Shek 2019). In contrast, there was an inverse relationship between dysfunctional parenting such as psychologically controlling and well-being among adolescents (van der Kaap-Deeder et al. 2017).

Based on above discussion, it makes sense to expect mediating effects of parental factors for the associations between adolescents' maladaptive behavior (e.g., externalizing and internalizing problems) and their LS. However, this possibility has not been directly tested so far. Furthermore, as highlighted by Shek (2014), studies on quality of life in relation to Chinese families are sparse. Thus, the current study endeavored to fill this research gap by using a Chinese adolescent sample in Hong Kong, who were followed up during their 3-year junior high school stage. To test the mediating effects of parental factors, we focused on three important processes of parent-child subsystem quality, including behavioral control, psychological control, and quality of parent-child relationship. 
Through disciplinary strategies such as monitoring and setting explicit rules, behavior control aims to manage adolescents' behaviors. In contrast, psychological control implicitly manipulates adolescents' behaviors by controlling their thoughts, feelings, and emotions (Shek et al. 2018; Shek and Zhu 2019). While behavioral control represents a positive parenting strategy that is associated with favorable developmental outcomes among adolescents, psychological control is a type of dysfunctional parenting practice that harms adolescent development (Shek et al. 2018; Barber et al. 2005). The third concept, quality of parent-child relationship reflects the nature of parentchild dyads, such as the extent to which adolescents trust their parents, are willing to interact with parents, and fell satisfactory with parents' discipline (Shek et al. 2018). High-quality relationships between parents and their children can also contribute to adolescents' positive development and well-functioning (Shek and Zhu 2019; Wang et al. 2013).

\subsection{The Present Study}

The present study attempted to examine the influence of adolescent problem behavior on LS as well as the mediating effect of different aspects of parent-child subsystem quality that account for the effect of adolescents' problem behavior on their LS. Specifically, we aimed to address four research questions as follows:

(1). Do adolescent maladaptive behaviors indexed by externalizing and internalizing behavior predict their LS (i.e., main effect)? Based on the extant literature reviewed in the Introduction section, we expected that adolescent externalizing behavior (Hypothesis 1a) and internalizing behavior (Hypothesis 1b) would inversely predict their LS.

(2). Does parental behavioral control mediate the main effect? We hypothesized that behavioral control of both parents would mediate the hypothesized main effect. Specifically, the two parental factors were expected to be negatively associated with adolescent maladaptive behavior (Hypothesis 2a) while positively would predict adolescent LS (Hypothesis 2b).

(3). Does parental psychological control mediate the main predicting effect? It was hypothesized that psychological control of both parents has a mediating effect. The two parental factors were hypothesized to be positively linked with adolescents' problem behavior (Hypothesis 3a) and negatively predict adolescent LS (Hypothesis 3b).

(4). Does parent-child relational quality mediate the expected main predicting effect? Qualities of father-child and mother-child relationships were hypothesized to have mediating effects as well. Specifically, the two parental factors would have negative associations with adolescent maladaptive behavior (Hypothesis 4a) and positive associations with adolescent LS (Hypothesis $4 \mathrm{~b}$ ).

Figure 1 presents the conceptual model of expected relationships among adolescent maladaptive behavior, parent-child subsystem quality, and LS. To have a parsimonious view of the separate effect of each process of parent-child subsystem qualities, we focused on testing a corresponding model only including paternal and maternal factors in this process (i.e., two potential mediators). To portray a full-picture of the 


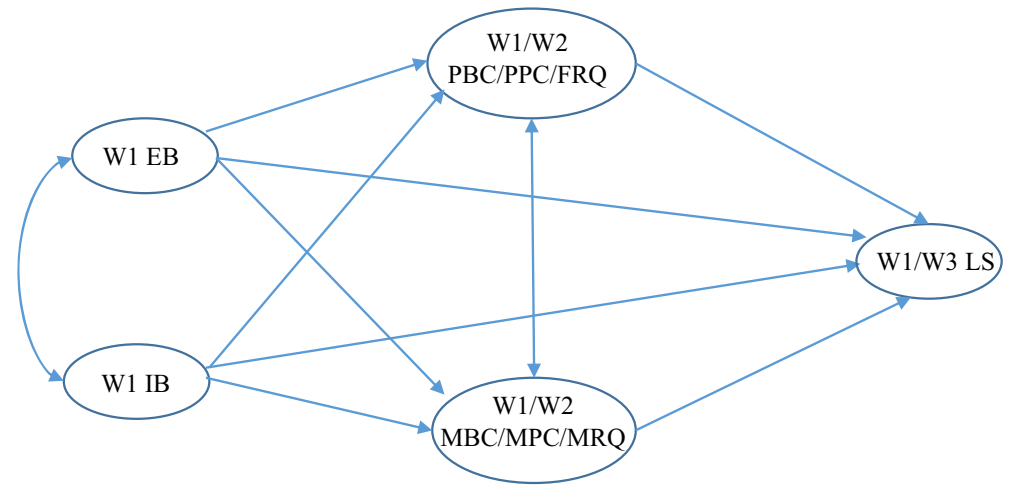

Fig. 1 Conceptual model on the relationships among adolescent maladaptive behaviors, parents' behavioral control, and life satisfaction. W1 = Wave 1, W2 = Wave 2, W3 = Wave 3. EB = Externalizing behavior, IB = Internalizing behavior, $\mathrm{PBC}=$ Paternal behavioral control, $\mathrm{PPC}=$ Paternal psychological control, FRQ = Father-child relational quality, MBC = Maternal behavioral control, MPC = Maternal psychological control, $\mathrm{MRQ}=$ Mother-child relational quality, LS = Life satisfaction. As different aspects of parent-child subsystem qualities were expected to be associated with adolescent maladaptive behaviors and their life satisfaction in different directions, the positivity or negativity of different paths are not shown in the figure

associations among adolescent problem behavior, parental factors, and adolescent LS, the present study investigated both cross-sectional models at each wave and longitudinal model (i.e., adolescent problem behavior at Wave 1 as the independent variable, parent-child subsystem quality at Wave 2 as mediators and adolescent LS at Wave 3 as the dependent variable). The investigation of cross-sectional models at each wave could also help explore whether there is any change in the associations among these variables.

When testing the proposed model depicted in Fig. 1, we also considered the effect of child gender, which may affect adolescents' maladaptive behavior and subsequent parental responses. Specifically, it has been well documented that adolescent girls have higher levels of internalizing problems than boys while boys have higher levels of externalizing behavior than girls (Lyons et al. 2014). Some scholars believed that parents are more responsive to adolescent girls and impose more control over daughters (Wertz et al. 2016). For example, it was observed that adolescent Internet addiction predict deteriorated family functioning in one year and such an effect was significant only among daughters (Ko et al. 2015). However, other studies reported that changes in parenting in response to the child's problem behavior are not moderated by child gender (Pinquart 2017; Wertz et al. 2016). In view of the inconclusive findings, we did not make a specific hypothesis about gender effect. However, we would conduct multi-group comparison (child gender: boys vs. girls) to ascertain invariance of findings across the gender samples before using the full sample to test the models shown in Fig. 1.

\section{Methods}

\subsection{Participants and Procedures}

The data used in the present study was derived from a longitudinal project launched in 2009/2010 academic year in Hong Kong. This project aimed to investigate the 
development of Chinese adolescents as well as the psychosocial determinants. The sampling method utilized in this project was cluster sampling method. First, in August 2009, based on a school list obtained from the Educational Bureau of Hong Kong government, the research team formed a candidate school pool including all 398 government or aided Chinese-speaking high schools located in different districts in Hong Kong. Second, 30 schools were randomly selected from the pool and they were invited to participate in the project. An alternate school randomly selected from the same district was invited if the originally selected school did not accept our invitation. After four rounds of inviting, a total of 28 schools, including 5 in Hong Kong Island, 7 in Kowloon, and 16 in New Territories, agreed to join the project. Third, in the 2009/ 2010 academic year, there were 4531 junior Secondary 1 (i.e., Grade 7) students in these participating schools and these students formed the adolescent population who were invited to complete the same survey annually during their high school stage.

Ethical approval was obtained from the "Human Subjects Ethics Sub-committee" (HSESC) or its Delegate of the authors' university. The purpose and procedure of the project and important principles such as confidentiality were explained to the participating schools, student participants, and their parents, and all these involved parties provided their informed written consent.

The current study adopted 3-wave data that collected in three consecutive years during adolescent participants' junior secondary school stage. While the population of participants $(N=4531$, Grade 7 students in 2009/2010) remained the same across waves, the number of respondents who completed the survey varied at Wave 1 (i.e., $N=3328, M_{\text {age }}=12.59 \pm .74$ years, $52.15 \%$ boys), Wave 2 (i.e., $N=3638, M_{\text {age }}=$ $13.64 \pm .75$ years, $52.06 \%$ boys $)$, and Wave $3\left(N=4106, M_{\text {age }}=14.65 \pm .79\right.$ years, $53.68 \%$ boys) due to student absence at the time of data collection. The response rate at the three waves was $73.45 \%, 80.29 \%$, and $90.62 \%$, respectively. Data provided by these participants were used for cross-sectional analyses at each wave. Concerning the demographic profile of general Chinese Hong Kong adolescent population at Grade 7 in 2009/2010 (i.e., mean age $=12.04$ years, 52.46\% boys) (Education Bureau 2010), the present sample of adolescents had good representativeness.

Among the 3328 students who completed the survey at Wave 1, 2905 and 2860 completed the survey at Wave 2 (attrition rate $=12.70 \%$ ) and Wave 3 (attrition rate = $14.10 \%$ ), respectively. The attrition rates can be regarded as low when compared to some of the published longitudinal studies (Archer et al. 2019; Riley et al. 2019). The matched sample $(N=2669)$ who completed the survey at all the three waves was utilized in present longitudinal analyses. The average age of the matched sample at Wave 1 was 12.56 years old and $49.6 \%(n=1324)$ of them were boys. Overall speaking, the matched sample also possessed comparable demographic profile to the general adolescent population.

Comparisons between the matched sample $(N=2669)$ and the dropouts from Wave $1(N=659)$ showed that the matched sample was slightly younger and included a slightly higher percentage of girls. For baseline parental factors at Wave 1, the two samples did not differ from each other in fathers' behavioral control. However, the matched sample reported slightly higher maternal behavioral control, slightly lower paternal and maternal psychological control, and slightly higher quality of father- and mother-adolescent relationships. For baseline problem behaviors, the matched sample reported slightly lower mean scores in the measures of externalizing and internalizing 
behavior. As the effect sizes of differences in baseline conditions between the two samples were not large, attrition was not a major bias in the longitudinal analyses in the present study.

\subsection{Instruments}

Maladaptive behavior as indexed by externalizing and internalizing behavior, parentchild subsystem quality, and LS were the foci of the current study. Externalizing behavior was measured in terms of "risk and delinquent behavior" and "problem behavioral intention", internalizing behavior was assessed by "deliberate self-harm" and "suicidal behavior". All measures involved in the present study were elaborated as follows. Risk and delinquent behavior was assessed by the number of times that the participants had twelve behavioral problems during previous one year, including "stealing", "cheating", "truancy", "running away from home", "damaging others' properties", "beating others", "having sexual intercourse with others", "gang fighting", "speaking foul language", "staying outside the home overnight without parental consent", "bullying", and "trespassing". A 7-point scale was used with a higher score representing a higher level of externalizing behavior. The mean score of the scale was computed. In the current study, this scale showed acceptable internal consistency with Cronbach's $\alpha$ s ranging from .67 to .81 across waves (see Table 1). Problem behavioral intention was assessed by a 5-item scale which the participants indicated their willingness ( 1 = "absolutely will not", 4 = "absolutely will") to engage in the listed problem behaviors within the following two years, including "drinking", "smoking", "gambling", "drug abuse", and "having sexual intercourse". An average score across the five items was computed. The Cronbach's $\alpha$ s of the scale ranged between .71 and .73 (see Table 1), suggesting that the scale had acceptable reliability in the present study. Deliberate self-harm was measured using 17 dichotomous items ( $1=$ "no", $2=$ "yes"). The participants reported their engagement in the 17 forms of self-harm behavior in the past one year, including "wrist cutting", "burning with cigarette", "burning with fire", "carving words on the body", "carving other marks on the body", "self-scratching", "self-biting", "rubbing sandpaper against the body", "acid dripping", "bleach scrubbing", "putting sharp objects into the body", "rubbing glass against the body", "breaking bones", "head banging", "self-punching", "preventing wounds from healing", and "self-harm using other methods". The mean score of the scale was calculated to represent one's deliberate self-harm behavior. This scale was internally consistent with Cronbach's $\alpha$ s ranging between .84 and .86 (see Table 1). Suicidal behavior was assessed using three items where the participants reported whether they had "suicidal thoughts", "plans", and "attempts", respectively, in the past 12 months (1 = "no", 2 = "yes"). The average score of the three items was used. The Cronbach's $\alpha$ s ranged from .66 to .70 (see Table 1), suggesting acceptable reliability of the scale in this study. Parent-child subsystem quality was measured by a validated scale named as "Parent-Child Subsystem Quality Scale" (PCSQS), which had good psychometric properties (Shek and Law 2016). The scale has two 17-item subscales which measured father- and mother-child subsystems, respectively. Each subscale measured three aspects of each subsystem, including behavioral control, psychological control, and relational quality. More specifically, 7 items in each subscale measured paternal/ maternal behavioral control (e.g., "My father/mother asked me about what I did after 
Table 1 Reliability of scales and descriptions of variables across the three waves

\begin{tabular}{|c|c|c|c|c|c|c|}
\hline Scale/Variable & & Wave & $\begin{array}{l}\text { Cronbach's } \\
\alpha\end{array}$ & Range & Mean & $S D$ \\
\hline \multirow[t]{6}{*}{ Externalizing behavior } & \multirow[t]{3}{*}{ Risk and delinquent behavior } & Wave 1 & 67 & $0-6$ & .36 & .39 \\
\hline & & Wave 2 & .77 & $0-6$ & .44 & .48 \\
\hline & & Wave 3 & .81 & $0-6$ & .44 & .48 \\
\hline & \multirow[t]{3}{*}{ Problem behavioral intention } & Wave 1 & .71 & $1-4$ & 1.24 & .36 \\
\hline & & Wave 2 & .73 & $1-4$ & 1.32 & .43 \\
\hline & & Wave 3 & .73 & $1-4$ & 1.36 & .45 \\
\hline \multirow[t]{6}{*}{ Internalizing behavior } & \multirow[t]{3}{*}{ Deliberate self-harm } & Wave 1 & .84 & $1-2$ & 1.03 & .08 \\
\hline & & Wave 2 & .86 & $1-2$ & 1.04 & .09 \\
\hline & & Wave 3 & .85 & $1-2$ & 1.03 & .08 \\
\hline & \multirow[t]{3}{*}{ Suicidal behavior } & Wave 1 & .66 & $1-2$ & 1.07 & .19 \\
\hline & & Wave 2 & .70 & $1-2$ & 1.07 & .20 \\
\hline & & Wave 3 & .69 & $1-2$ & 1.06 & .18 \\
\hline \multirow[t]{3}{*}{ Life satisfaction } & & Wave 1 & .86 & $1-6$ & 3.96 & 1.06 \\
\hline & & Wave 2 & .88 & $1-6$ & 3.83 & 1.08 \\
\hline & & Wave 3 & .88 & $1-6$ & 3.77 & 1.05 \\
\hline \multirow[t]{9}{*}{ Father-child subsystem quality } & \multirow[t]{3}{*}{ Paternal behavioral control } & Wave 1 & .89 & $1-4$ & 2.56 & .67 \\
\hline & & Wave 2 & .89 & $1-4$ & 2.53 & .64 \\
\hline & & Wave 3 & .89 & $1-4$ & 2.50 & .63 \\
\hline & \multirow[t]{3}{*}{ Paternal psychological control } & Wave 1 & .80 & $1-4$ & 2.24 & .72 \\
\hline & & Wave 2 & .83 & $1-4$ & 2.26 & .72 \\
\hline & & Wave 3 & .86 & $1-4$ & 2.22 & .74 \\
\hline & \multirow[t]{3}{*}{ Father-child relational quality } & Wave 1 & .90 & $1-4$ & 2.80 & .70 \\
\hline & & Wave 2 & .91 & $1-4$ & 2.76 & .69 \\
\hline & & Wave 3 & .90 & $1-4$ & 2.75 & .67 \\
\hline \multirow{9}{*}{$\begin{array}{l}\text { Mother-child subsystem } \\
\text { quality }\end{array}$} & \multirow[t]{3}{*}{ Maternal behavioral control } & Wave 1 & .90 & $1-4$ & 3.03 & .62 \\
\hline & & Wave 2 & .89 & $1-4$ & 2.96 & 60 \\
\hline & & Wave 3 & .89 & $1-4$ & 2.91 & .58 \\
\hline & \multirow{3}{*}{$\begin{array}{l}\text { Maternal psychological } \\
\text { control }\end{array}$} & Wave 1 & .85 & $1-4$ & 2.31 & .77 \\
\hline & & Wave 2 & .88 & $1-4$ & 2.31 & .76 \\
\hline & & Wave 3 & .89 & $1-4$ & 2.27 & .76 \\
\hline & \multirow{3}{*}{$\begin{array}{l}\text { Mother-child relational } \\
\text { quality }\end{array}$} & Wave 1 & .91 & $1-4$ & 3.05 & .67 \\
\hline & & Wave 2 & .91 & $1-4$ & 2.96 & .66 \\
\hline & & Wave 3 & .90 & $1-4$ & 2.96 & .62 \\
\hline
\end{tabular}

school", "my father/mother expects me to have good behavior in school" and "my father/mother actively understands my afterschool activities"). Another 4 items of each subscale measured paternal/maternal psychological control (e.g., "Father/mother often wants to change my mind or feelings for things"). The final 6 items measured quality of father-/mother-child relationship (e.g., "My father's/mother's discipline of me is reasonable" and "I shared my feelings with my father/mother"). A 4-point Likert scale was adopted ( $1=$ "strongly disagree", 4 = "strongly agree") and the average score in 
each aspect of each subscale was calculated. In the current study, all subscales of the PCSQS were regarded as internally consistent as indicated by Cronbach's $\alpha$ s which ranged from .80 to .91 (see Table 1).

Life Satisfaction The validated Chinese version of the 5-item "Satisfaction with Life Scale" (SWLS) was used to measure adolescents' global LS in the present study. This scale has been frequently used in previous studies on LS in Chinese context (Shek et al. 2017). A 6-point scale ranging from 1 ("strongly disagree") to 6 ("strongly agree") was used. The Cronbach's $\alpha$ s of the scale ranged between .86 and .88, suggesting good reliability across waves (see Table 1 ).

\subsection{Data Analysis}

Data analyses including reliability analyses, descriptive statistics, and correlational analyses were performed using SPSS (version 25.0, IBM Corp., Somers, NY, USA). Structural equation modeling (SEM) was utilized for the investigation of models depicted in Fig. 1 by using AMOS (version 25.0 IBM Corp., Somers, NY, USA). When doing SEM, externalizing and internalizing behavior, the specific aspects of parent-child subsystem quality, and adolescent LS were treated as latent variables. Specifically, composite scores of "risk and delinquent behavior" and "problem behavioral intention" were two observed indicators of externalizing behavior. Likewise, scores "deliberate self-harm" and "suicidal behavior" were indicators of internalizing behavior. Indicators of other latent variables were items of corresponding measuring scales.

Several indices were used to assess the model fit, including "Goodness of Fit Index" (GFI), "Comparative Fit Index" (CFI), "Incremental Fit Index" (IFI), "Non-Normed fit index" (NNFI), and "Root Mean Square Error of Approximation" (RMSEA). For GFI, CFI, IFI, and NNFI, a value higher than .90 suggests acceptable goodness-of-fit (Kline 2015). As for RMSEA, a value below .80 indicates an adequate model fit (Kline 2015). To test mediating effects of parental factors with more accuracy, we performed bootstrapping with 10,000 times of re-sampling and calculated bias-corrected (BC) 95\% confidence intervals (CI) (Preacher and Hayes 2008).

We first performed multi-group comparisons based on child gender to decide if it is appropriate to test the mediating models using the full sample. We compared model fitness between a constrained model and an unconstrained model for each proposed mediating model. Specifically, in the constrained model, the regression weights of the corresponding predicting paths were constrained to be constant across the two groups (boys vs. girls) while in the unconstrained model, all the regression weights were freely to be estimated. If the constrained model can be accepted (i.e., the model fitness does not get worse), which means the regression weights are constant between girls and boys, it will then be appropriate to test the proposed mediating effects based on the whole sample.

\section{Results}

Tables 1 and 2 present results of descriptive and correlational analyses, respectively. It can be seen that adolescent boys had higher levels of externalizing behavior while girls 


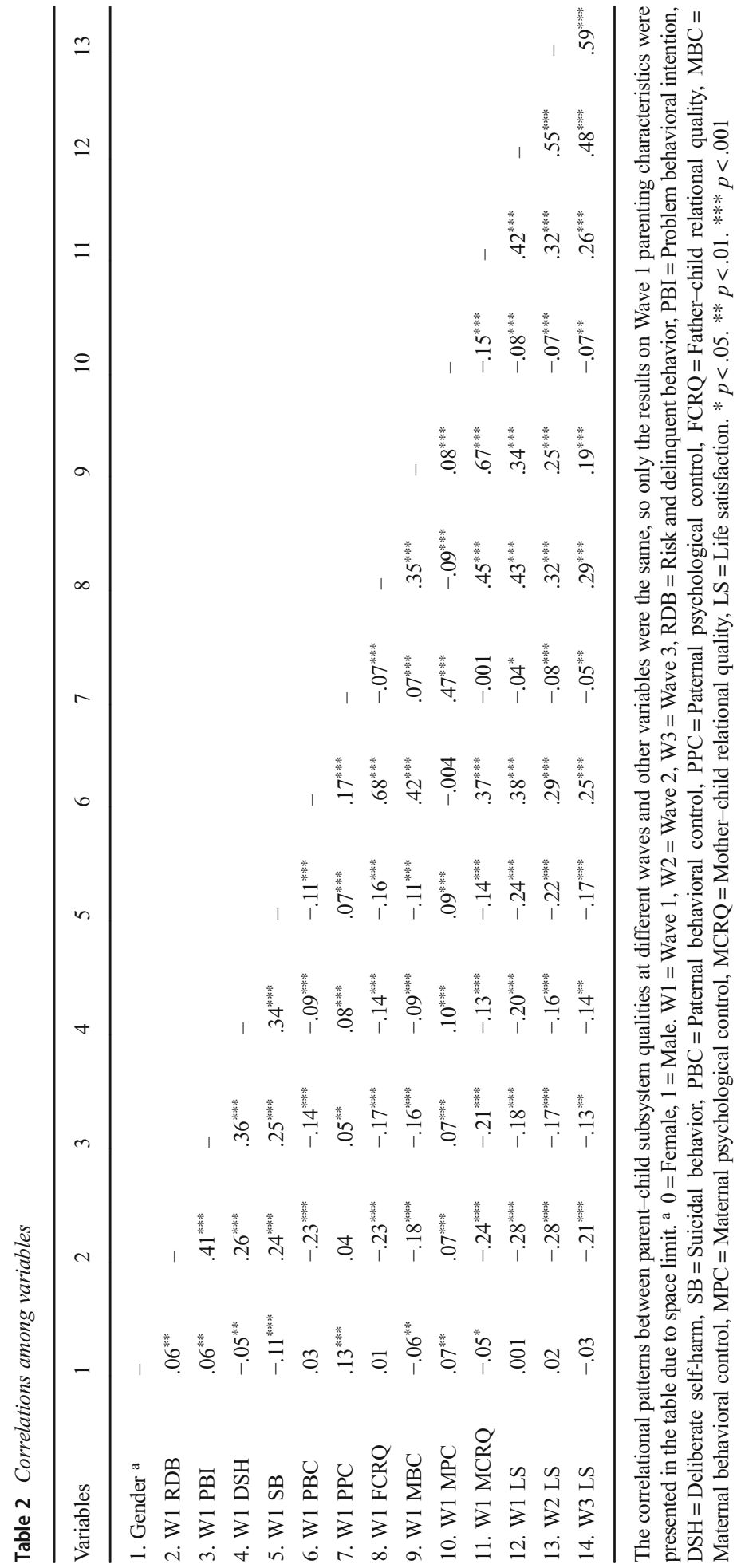


reported higher levels of internalizing behavior. As expected, both externalizing and internalizing behavior had negative cross-sectional and longitudinal associations with LS. In addition, adolescent problem behavior was negatively associated with parental behavioral control and parent-child relational quality, which, as expected, were positively associated with adolescent LS. Furthermore, adolescent maladaptive problems were positively correlated with parental psychological control, which was negatively associated with adolescent LS.

\subsection{Preliminary Analyses}

Measurement models including nine latent variables (i.e., externalizing and internalizing behaviors, six parental factors, and adolescent LS) and their indicators were tested using cross-sectional (i.e., data at each wave) and longitudinal data. These measurement models showed good model fit with GFI above .92, CFI and IFI higher than .93, NNFI higher than .91, and RMSEA ranging from .04 to .06.

Multi-group comparisons revealed that constrained models were acceptable with GFI, CFI, IFI, and NNFI higher than .90 and RMSEA ranging between .02 and .04. Furthermore, chi-square difference tests did not show significant differences between the unconstrained and corresponding constrained model for the cross-sectional as well longitudinal models ( $\Delta \chi^{2}$ ranged between 8.27 to 15.19 with $\Delta d f=8, p>.05$ ). These results suggested that gender did not affect the relationships among the included variables in the model. Thus, the following sections present the results of SEM based on the whole sample.

\subsection{Adolescent Maladaptive Behavior and their LS}

The results of SEM on the hypothesized relationships among adolescent maladaptive behavior, parent-child subsystem quality, and adolescent LS are depicted in Fig. 2 (i.e., cross-sectional model) and Fig. 3 (i.e., longitudinal model). As the patterns of crosssectional relationships among these variables were the same across the three waves, only results of Wave 1 are presented in Fig. 1. Overall speaking, both externalizing and internalizing behavior of adolescents negatively predicted their concurrent as well as future LS, either directly or indirectly through the mediating effects of parent-child subsystem quality (see Table 3 for a summary of the effects). Thus, Hypothesis 1a and $1 \mathrm{~b}$ were supported.

\subsection{Mediating Effects of Parental Behavioral Control}

As shown in Fig. 2A and Fig. 3A, while both fathers' and mothers' behavioral control showed significant mediating effects on the cross-sectional and longitudinal relationships between adolescent externalizing behavior and their LS, neither fathers' nor mothers' behavioral control served as a significant mediator underlying the relationship between internalizing behavior and adolescent LS. A summary of the effects is presented in Table 3. Specifically, while adolescent externalizing behavior at Wave 1 negatively predicted their parents' behavioral control at Wave 1 (father: $\beta=-.31$, $p<.001$; mother: $\beta=-.30, p<.001$ ) and Wave 2 (father: $\beta=-.25, p<.001$; mother: $\beta=-.39, p<.001)$, adolescent internalizing behavior did not. Thus, Hypothesis 2 a was 


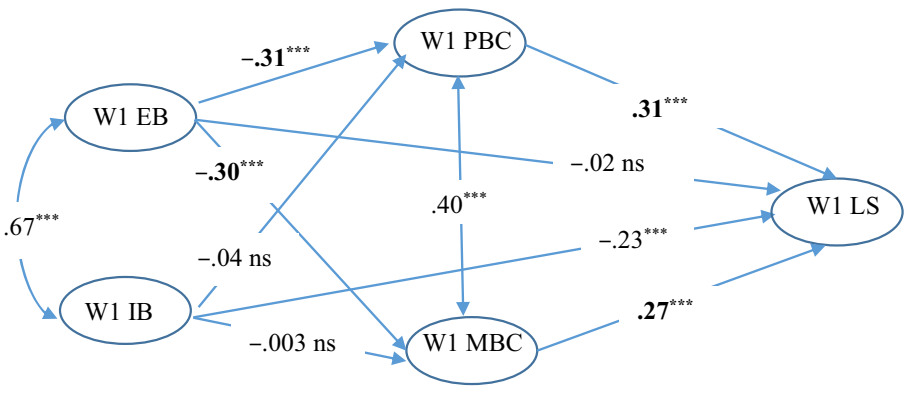

a $\mathrm{X}^{2}=376.28, d f=78, \mathrm{GFI}=.96, \mathrm{CFI}=.91, \mathrm{IFI}=.91, \mathrm{NNFI}=.90, \mathrm{RMSEA}=.03$

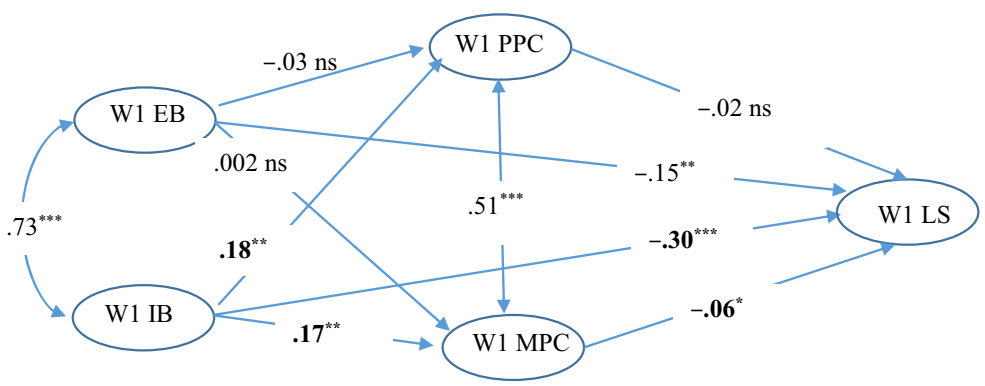

b $x^{2}=1035.42, d f=107, \mathrm{GFI}=.96, \mathrm{CFI}=.96, \mathrm{IFI}=.96, \mathrm{NNFI}=.95, \mathrm{RMSEA}=.05$

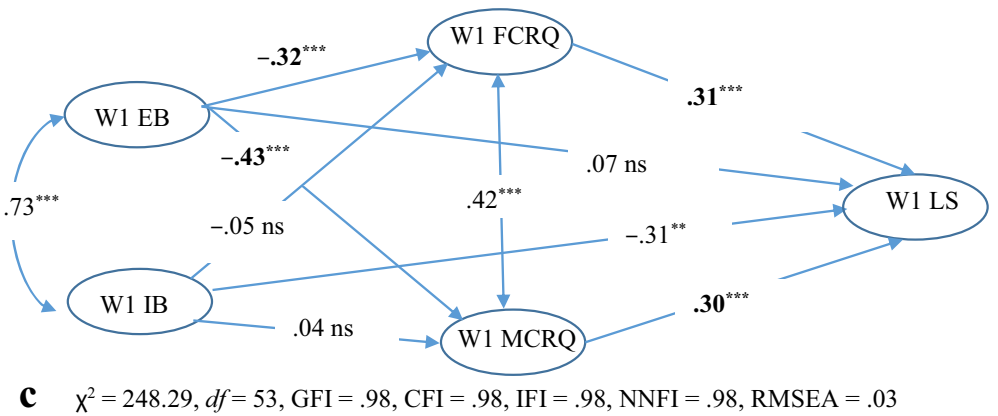

Fig. 2 Cross-sectional relationships among adolescent maladaptive behaviors, parent-child subsystem qualities, and adolescent life satisfaction. Because the pattern of results for each wave is the same, only results of Wave 1 were presented. $\mathrm{W} 1=$ Wave $1, \mathrm{~EB}=$ Externalizing behavior, $\mathrm{IB}=$ Internalizing behavior, $\mathrm{PBC}=$ Paternal behavioral control, $\mathrm{MBC}=$ Maternal behavioral control, $\mathrm{PPC}=$ Paternal psychological control, MPC $=$ Maternal psychological control, FCRQ $=$ Father-child relational quality, MCRQ $=$ Mother-child relational quality, LS $=$ Life satisfaction. $* p<.05$. $* * p<.01$. *** $p<.001$

partially supported. Regarding Hypothesis $2 \mathrm{~b}$, it was supported as both parents' behavioral control showed a significant and positive predicting effect on adolescents' concurrent (father: $\beta=.31, p<.001$; mother: $\beta=.27, p<.001$ ) and later LS (father: $\beta=.20, p<.001$; mother: $\beta=.21, p<.001$ ). Therefore, Hypothesis $2 \mathrm{~b}$ was supported.

\subsection{Mediating Effects of Parental Psychological Control}

Based on Fig. 2B and 3B, paternal psychological control did not show the expected mediating effects. Regarding mothers' psychological control, it only exerted a weak 


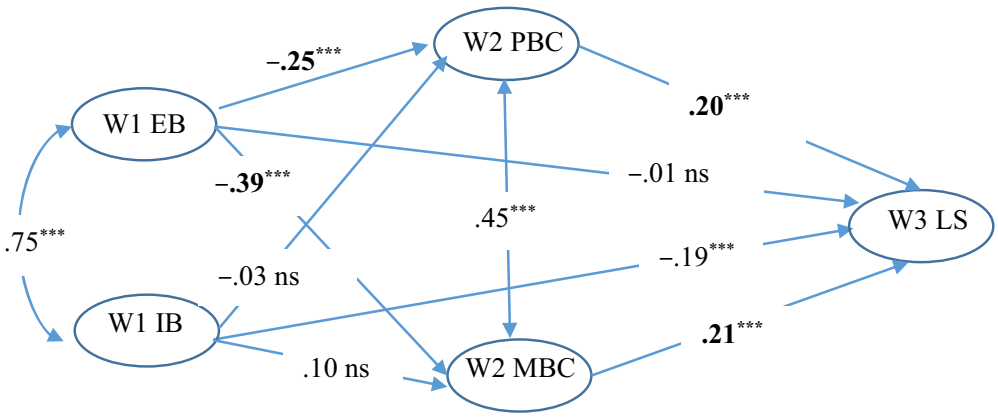

a $\mathrm{X}^{2}=336.99, d f=78, \mathrm{GFI}=.98, \mathrm{CFI}=.98, \mathrm{IFI}=.98, \mathrm{NNFI}=.98, \mathrm{RMSEA}=.04$

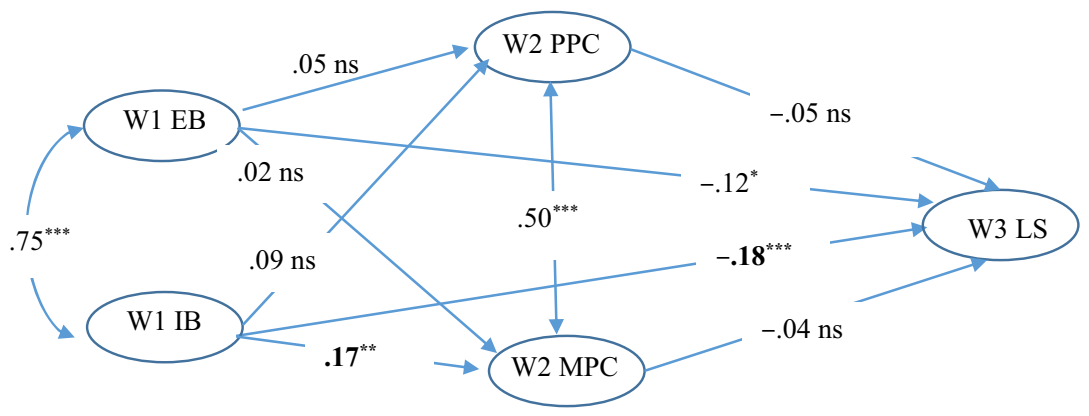

b $X^{2}=700.79, d f=107, \mathrm{GFI}=.97, \mathrm{CFI}=.97, \mathrm{IFI}=.97, \mathrm{NNFI}=.96, \mathrm{RMSEA}=.05$

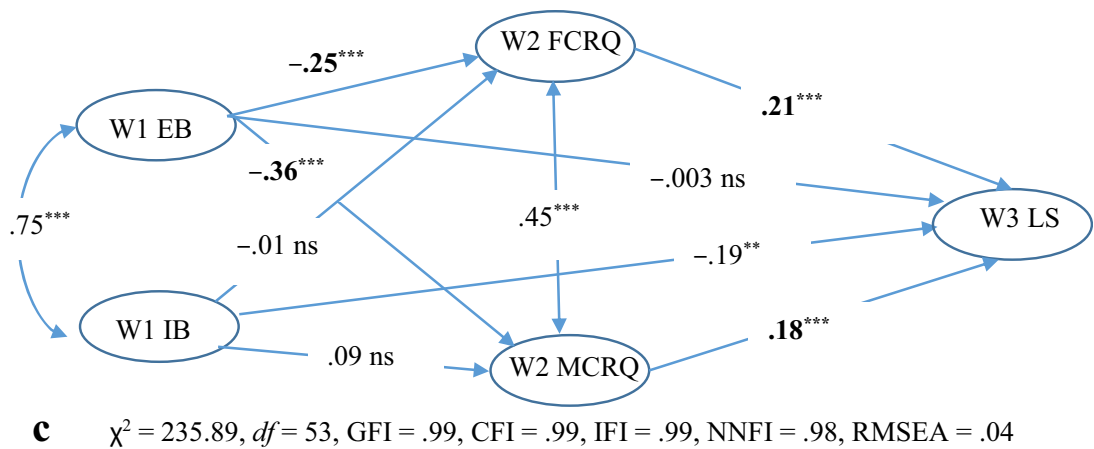

Fig. 3 Longitudinal relationships among adolescent maladaptive behaviors, parent-child subsystem qualities, and adolescent life satisfaction. W1 = Wave 1, W2 = Wave 2, W3 = Wave 3, EB = Externalizing behavior, IB = Internalizing behavior, $\mathrm{PBC}=$ Paternal behavioral control, $\mathrm{MBC}=$ Maternal behavioral control, $\mathrm{PPC}=$ Paternal psychological control, MPC = Maternal psychological control, FCRQ $=$ Father-child relational quality, MCRQ $=$ Mother-child relational quality, LS $=$ Life satisfaction. ${ }^{*} p<.05 . * * p<.01 .{ }^{* * *} p<.001$

mediating effect on the cross-sectional relationship between adolescent internalizing behavior and their LS (see Fig. 2B and Table 3). Specifically, adolescent externalizing behavior did not predict their parents' current or longitudinal psychological control. However, while internalizing behavior positively predicted both parents' concurrent psychological control (father: $\beta=.18, p<.01$; mother: $\beta=.17, p<.01$ ), it only predicted mothers' psychological control in one year $(\beta=.17, p<.01)$. Therefore, Hypothesis 


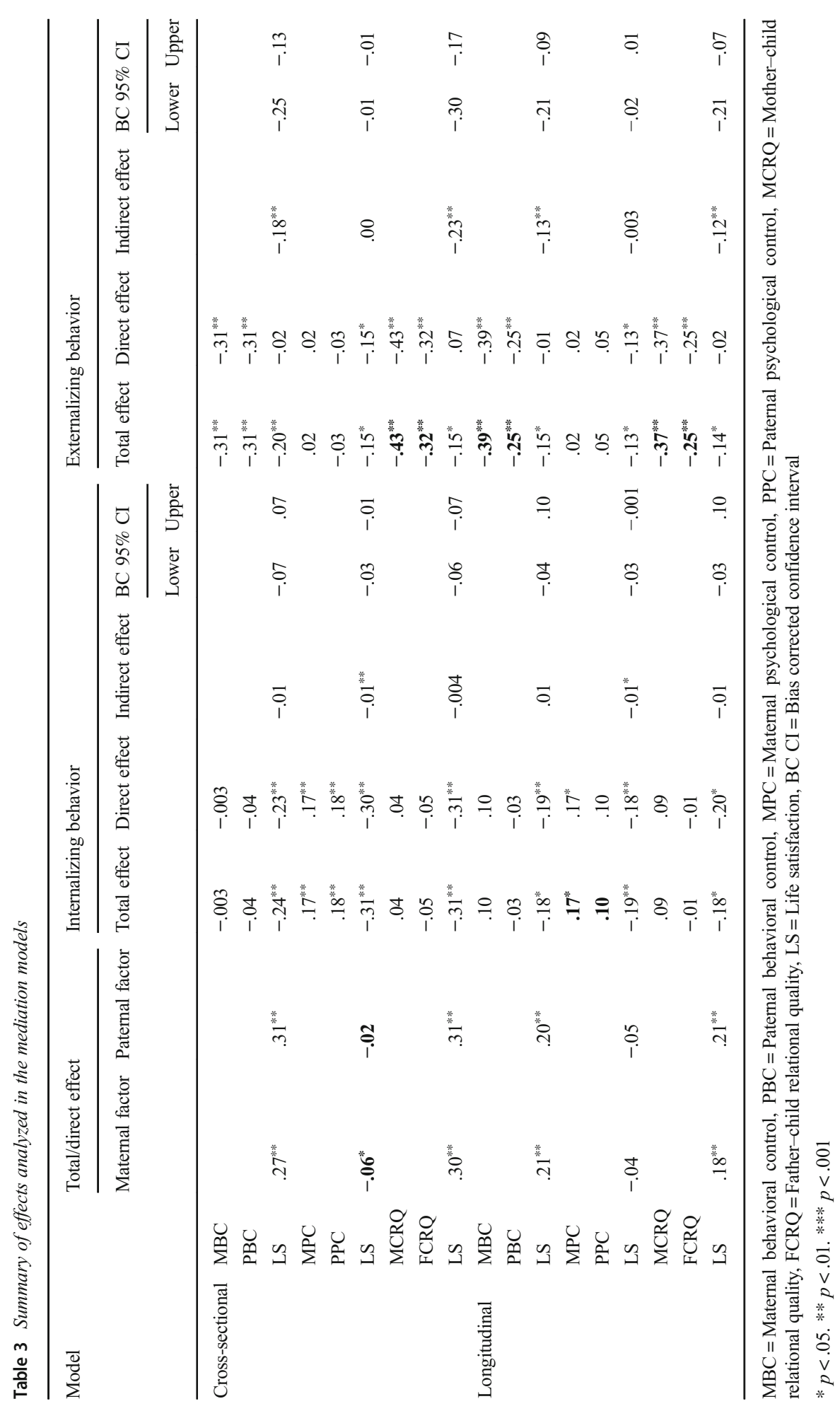


3a was partially supported. While fathers' psychological control did not show any predicting effects on adolescent LS, mother's psychological control showed a weak cross-sectional predicting effect $(\beta=-.06, p<.05$, see Fig. $2 \mathrm{~B}$ and Table 3$)$, but no longitudinal predicting effect $(\beta=-.04, p>.05$, see Fig. $3 \mathrm{~B})$ on adolescent LS. Thus, Hypothesis $3 \mathrm{~b}$ was partially supported as well.

\subsection{Mediating Effects of Parent-Child Relational Quality}

Quality of both father- and mother-child relationships served as significant mediators underlying the cross-sectional and longitudinal relationships between adolescent externalizing behavior and their LS (see Fig. 2C and 3C and Table 3). However, the relationships between internalizing behavior and LS were not significantly mediated by parent-child relationship quality. To illustrate, adolescent externalizing behavior at Wave 1 negatively predicted the quality of father-child relationship at Wave 1 ( $\beta=$ $-.32, p<.001)$ and Wave $2(\beta=-.25, p<.001)$, and the quality of mother-child relationship at Wave $1(\beta=-.43, p<.001)$ and Wave $2(\beta=-.36, p<.001)$. However, adolescent internalizing behavior did not show any significant predicting effects on qualities of parent-child relationships. Therefore, Hypothesis $4 \mathrm{a}$ was partially supported. As father- and mother-child relational qualities showed significant and positive predicting effects on adolescents' concurrent (father: $\beta=.31, p<.001$; mother: $\beta=.30$, $p<.001$ ) and later LS (father: $\beta=.21, p<.001$; mother: $\beta=.18, p<.001$ ), Hypothesis $4 \mathrm{~b}$ was supported.

As it can be argued that the inclusion of three family processes in a single mediation model would offer another meaningful perspective, we also attempted to look at all the six parental factors in a single model. Unfortunately, probably because of the issue of multi-collinearity, the model was an unidentified model (Tarka 2018). Hence, we subsequently included only paternal and maternal behavioral control as well as their psychological control as four mediating factors in a single model (i.e., dropping father- and mother-child relationship), the model fit was acceptable (GFI, CFI, IFI higher than .92, NNFI higher than 90, RMSEA ranging between .06 and .07) and the pattern of regression weights was in line with that in the separate model and the hypotheses. As it is more parsimonious to focus on separate process of parent-child subsystem qualities, the present paper discusses the mediating effect of each family process which can help us understand the discrete mechanisms of different family processes.

\section{Discussion}

As Lyons et al. (2013) pointed out, "quality of life research is only just beginning to elucidate the psychological mechanisms through which life satisfaction develops, is maintained, or change over time" (p. 594). The present study added value to this research field by investigating how adolescent externalizing and internalizing problems affect their life satisfaction (LS) through the mediating effects of different aspects of parent-child subsystem quality. As expected, both externalizing and internalizing problems lead to deterioration of LS among early Chinese adolescents in Hong Kong. 
Previous literature has also documented the negative associations between adolescent maladaptive behavior and their LS (e.g., Bartels et al. 2013; Schei et al. 2016). Our study further extended this conclusion by examining it longitudinally.

Overall speaking, both paternal and maternal factors, particularly parental behavioral control and the quality of parent-child relationships, mediated the effects of maladaptive behavior on LS among early adolescents. Regarding the mediating effects, several findings could be highlighted. First, adolescents' higher externalizing behavior predicted lower parental behavioral control and poorer parent-child relationship. This observation echoes previous findings that parents became less warm, less supportive, and disengaged (e.g., less behavioral monitoring) in response to their children's antisocial activities (Pinquart 2017; Williams and Steinberg 2011; Dishion et al. 2004).

Second, while some previous studies also found that externalizing behavior elicited greater parental harshness and psychological control (Pinquart 2017; Albrecht et al. 2007), the present study did not identify such an effect. Our results imply that Chinese parents might be more likely to respond to their children's externalizing behaviors by decreasing positive forms of parenting rather than increasing dysfunctional parenting. Even though in an undesirable way, increase in psychological control represents a certain kind of greater involvement in socializing children. Thus, overall speaking, parents may tend to be less devoted in facing children's misconduct. Another possibility is that the construct of psychological control may be conceived and interpreted differently in Chinese culture. In other words, elements of psychological control may be "accepted" by adolescents instead of interpreted as negative parenting.

Third, while some research showed that adolescents' with internalized distress experienced parental disengagement and less warm over time (Williams and Steinberg 2011), other research found that internalizing behavior, in comparison to externalizing behavior, had weaker impacts on parental support and parent-child relationship (Reitz et al. 2006). Likewise, the present study found that adolescent internalizing behavior tended not to affect parents' behavioral control and quality of parent-child relationship. Instead, it significantly increased parents', especially mothers' psychological control. This result seems consistent with previous studies which also reported a significant increase in parents' psychological controlling behaviors due to children's internalizing problems (Rogers et al. 2003; Albrecht et al. 2007). Parents might respond to adolescents' emotional difficulties by blaming and manipulating their children's emotions and thought patterns. From the perspective of parents, it appears to be reasonable to react to children's internalizing problems with intrusive parenting to stop the child from displaying negative emotions and feeling depressed (Albrecht et al. 2007). An alternative explanation is that adolescents with internalizing problems may also suffer from cognitive bias which make them interpret their parents' behaviors as more psychological controlling (Rogers et al. 2003). Fourth, behavioral control and parent-child relationship served as positive predictors of adolescent concurrent and future LS. These findings are in line with other studies showing that positive parental factors (e.g., support, consistent behavioral control, and positive interactions between parents and children) promote the development of children's well-being (van der Kaap-Deeder et al. 2017; Raboteg-Saric and Sakic 2014). Nevertheless, the present study did not observe a strong effect of parents' psychological control on adolescents' LS. This is incongruent with a notion that high psychological control may inhibit the fulfillment of psychological needs and lead to bad feelings 
about oneself and one's life (van der Kaap-Deeder et al. 2017; Shek 2007; Leung and Shek 2019). However, it is argued that psychological control is not necessarily harmful in Chinese culture because adolescents may interpret it as a way of showing love and concern (Shek et al. 2019; Chen 2014). Indeed, Chen (2014) reported that parents' harsh controlling behavior was positively related to children's filial piety. Therefore, more studies are needed to test this conjecture and explore whether and how psychological control affects child development in Chinese communities.

Fifth, regarding child gender effect, girls were found to show higher levels of internalizing behavior and lower levels of externalizing behavior than boys. The findings are consistent with previous observations (Bartels et al. 2013). These findings suggest that boys are more likely to direct difficulties they had experienced outward to others and external environment. In contrast, girls are more oriented to keep difficulties to themselves and act negatively toward internal psychological system, thus suffering internalizing distress and emotional problems. However, no other significant effects of child gender were identified in the present study. In other words, the relationships among maladaptive behavior, parent-child subsystem quality, and LS were not significantly moderated by child gender. The findings seem in accordance with previous evidence that parents responded to sons' and daughters' behavioral problems in the same way (Albrecht et al. 2007; Rogers et al. 2003), and child gender differences were not prominent regarding parental influence on children's LS (Shek 2007).

Sixth, the present findings also shed light on differences in maternal versus paternal impacts. On the one hand, the associations between adolescent problem behavior and parental factors appeared to be stronger among mothers than fathers. For example, internalizing behavior only predicted subsequent mothers', but not fathers' psychological control in one year. This finding generally suggest that mothers may be more responsive to children's developmental problems, especially internalizing problems, by raising psychological control, or fathers may see children's emotional problems less significant than mothers. This conjecture echoes the consensus that mothers are more sensitive and attentive to their children's emotional and behavioral problems as they are more engaged in direct caregiving and typical socialization process than fathers (Wertz et al. 2016; McKinney and Renk 2008). However, there are also previous empirical findings showing similar responses to children's problem behaviors between mothers and fathers (Gault-Sherman 2012; Pinquart 2017). Given the equivocal findings, more studies are needed to draw a conclusive picture in this research field.

On the other hand, fathers' and mothers' behavioral control and their relationships with children showed similar positive influences on adolescent LS. However, while mothers' psychological control served as a weak cross-sectional predictor of adolescent LS, fathers' psychological control did not. Some scholars argued that mothers were more psychologically controlling than fathers and thus mathers' psychological control exerted greater negative impacts on child development (Giles and Price 2008). In line with notion, our finding suggests that adolescent LS might be also more susceptible to the negative influence of mothers' psychological control. Nevertheless, the magnitude of such a difference was not large in the present study and did not present in the longitudinal model. Thus, more future studies should be carried out to verify the presenting findings.

The clarification of relationships between adolescent maladaptive behavior and their LS as well as the mediating effects of parental factors has major implications for youth 
service and parent education. On the one hand, it is necessary to promote LS or prevent decrease in LS through protecting adolescents from developing maladaptive behavior. In these aspects, positive youth development programs could be a good choice to help adolescents develop the necessary competence and skills to resist risk factors of developing externalizing and internalizing behavior (Catalano et al. 2012; Shek 2019; Lerner et al. 2013). Besides, children with maladaptive problems may be more likely to evaluate parenting practices as more intrusive and less warm (Rogers et al. 2003). As these negative perceptions will also lead to a decrease in perceived quality of life, it is especially essential to nurture social skills among adolescents so that they are able to effectively communicate with parents, understand parents' good intentions, and have unbiased perception of parental strategies.

On the other hand, Shek and Siu (2019) pointed out that parenting problem is a risk factor in adolescent development. The present findings suggest that the promotion of parental behavioral control and parent-child relationship and reduction of parental psychological control would promote LS in adolescents. Parental reactions, such as disengagement, less monitoring, blaming, and criticizing, may result from parents' misunderstanding of children's behavioral and emotional difficulties. For example, they may expect that psychological control can help adolescents to get rid of negative emotions. Besides, children's emotional problems can lead to parents' negative emotional responses (Rogers et al. 2003), which may in turn result in dysfunctional parenting. Therefore, efforts can be made to help parents better understand adolescents' behavioral symptoms and emotional difficulties as well as factors causing these problems. In this way, parents will have sufficient knowledge and skills to appropriately redirect potentially ineffective parenting strategies and react to children's maladaptive problems in a functional way.

The present study has several limitations. First of all, all data were collected through adolescents' self-reporting. Some may argue that adolescents may misreport their problem behavior due to social desirability effect, and thus collecting data from significant others such as parents or teachers might be necessary. However, significant others may also misreport adolescents' conditions because adolescents may know their own conditions, such as emotional and behavioral difficulties and well-being, better than others. In addition, it might be their perception of parenting characteristics that really matters. Noteworthy, self-reporting measures are also widely used as a legitimate tool in youth studies (Archer et al. 2019; Massarwi et al. 2019). Nevertheless, it will be stimulating to triangulate or compare findings obtained from different informants. Second, while parental factors served as essential mediators in the present study, other mechanisms may also account for the relationships between maladaptive behavior and LS among adolescents. For example, adolescent problem behavior may harm their physical health or limit their socio-economic opportunities, which subsequently decreases their LS (Bogart et al. 2007). More studies are warranted to portray a holistic picture of the effects among these variables and associated mechanisms. Third, although we considered one-way effects among adolescents' maladaptive problems, parental characteristics, and adolescents' LS, some studies have outlined reciprocal effects among these factors (Pinquart 2017; Reitz et al. 2006; Proctor et al. 2009; Sun and Shek 2010, 2013). Therefore, future studies will benefit from further concerning models of reciprocal causal effects and examining possible mediators and moderators. 
Open Access This article is licensed under a Creative Commons Attribution 4.0 International License, which permits use, sharing, adaptation, distribution and reproduction in any medium or format, as long as you give appropriate credit to the original author(s) and the source, provide a link to the Creative Commons licence, and indicate if changes were made. The images or other third party material in this article are included in the article's Creative Commons licence, unless indicated otherwise in a credit line to the material. If material is not included in the article's Creative Commons licence and your intended use is not permitted by statutory regulation or exceeds the permitted use, you will need to obtain permission directly from the copyright holder. To view a copy of this licence, visit http://creativecommons.org/licenses/by/4.0/.

\section{References}

Albrecht, A. K., Galambos, N. L., \& Jansson, S. M. (2007). Adolescents' internalizing and aggressive behaviors and perceptions of parents' psychological control: A panel study examining direction of effects. Journal of Youth and Adolescence, 36(5), 673-684. https://doi.org/10.1007/s10964-007-9191-5.

Archer, C. M., Jiang, X., Thurston, I. B., \& Floyd, R. G. (2019). The differential effects of perceived social support on adolescent hope: Testing the moderating effects of age and gender. Child Indicators Research, 12, 2079-2094. https://doi.org/10.1007/s12187-019-9628-x.

Barber, B. K., Maughan, S. L., \& Olsen, J. A. (2005). Patterns of parenting across adolescence. New Directions for Child and Adolescent Development, 2005(108), 5-16. https://doi.org/10.1002/cd.124.

Bartels, M., Cacioppo, J. T., van Beijsterveldt, T. C., \& Boomsma, D. I. (2013). Exploring the association between well-being and psychopathology in adolescents. Behavior Genetics, 43(3), 177-190. https://doi. org/10.1007/s10519-013-9589-7.

Bell, R. Q. (1977). Socialization findings reexamined. In R. Q. Bell \& L. V. Harper (Eds.), Child effects on adults (pp. 53-84). Hillsdale, NJ: Erlbaum.

Bogart, L. M., Collins, R. L., Ellickson, P. L., \& Klein, D. J. (2007). Are adolescent substance users less satisfied with life as young adults and if so, why? Social Indicators Research, 81(1), 149-169. https://doi. org/10.1007/s11205-006-0019-6.

Catalano, R. F., Fagan, A. A., Gavin, L. E., Greenberg, M. T., Irwin, C. E., Ross, D. A., et al. (2012). Worldwide application of prevention science in adolescent health. The Lancet, 379(9826), 1653-1664. https://doi.org/10.1016/S0140-6736(12)60238-4.

Chen, W.-W. (2014). The relationship between perceived parenting style, filial piety, and life satisfaction in Hong Kong. Journal of Family Psychology, 28(3), 308-314. https://doi.org/10.1037/a0036819.

Danielsen, A. G., Samdal, O., Hetland, J., \& Wold, B. (2009). School-related social support and students' perceived life satisfaction. The Journal of Educational Research, 102(4), 303-320. https://oi. org/10.3200/JOER.102.4.303-320.

Desousa, C., Murphy, S., Roberts, C., \& Anderson, L. (2007). School policies and binge drinking behaviours of school-aged children in Wales-A multilevel analysis. Health Education Research, 23(2), 259-271. https://doi.org/10.1093/her/cym030.

Diener, E., Inglehart, R., \& Tay, L. (2012). Theory and validity of life satisfaction scales. Social Indicators Research, 112(3), 497-527. https://doi.org/10.1007/s11205-012-0076-y.

Dishion, T. J., Nelson, S. E., \& Bullock, B. M. (2004). Premature adolescent autonomy: Parent disengagement and deviant peer process in the amplification of problem behaviour. Journal of Adolescence, 27(5), 515530. https://doi.org/10.1016/j.adolescence.2004.06.005.

Bureau, E. (2010). Student enrolment statistics, 2009/10. Hong Kong: School Education Statistics Section, Education Bureau, Government of Hong Kong Special Administrative Region.

Evans, D. R. (1994). Enhancing quality of life in the population at large. Social Indicators Research, 33(1-3), 47-88. https://doi.org/10.1007/BF01078958.

Flaspohler, P. D., Elfstrom, J. L., Vanderzee, K. L., Sink, H. E., \& Birchmeier, Z. (2009). Stand by me: The effects of peer and teacher support in mitigating the impact of bullying on quality of life. Psychology in the Schools, 46(7), 636-649. https://doi.org/10.1002/pits.20404.

Fogle, L. M., Huebner, E. S., \& Laughlin, J. E. (2002). The relationship between temperament and life satisfaction in early adolescence: Cognitive and behavioral mediation models. Journal of Happiness Studies, 3(4), 373-392. https://doi.org/10.1023/A:1021883830847.

Fredrickson, B. L. (2001). The role of positive emotions in positive psychology: The broaden-and-build theory of positive emotions. American Psychologist, 56(3), 218-226. https://doi.org/10.1037/0003-066 X.56.3.218. 
Gault-Sherman, M. (2012). It'sa two-way street: The bidirectional relationship between parenting and delinquency. Journal of Youth and Adolescence, 41(2), 121-145. https://doi.org/10.1007/s10964-0119656-4.

Giles, G., \& Price, I. R. (2008). Adolescent computer use: Approach, avoidance, and parental control. Australian Journal of Psychology, 60(2), 63-71. https://doi.org/10.1080/00049530701829896.

Heffner, A. L., \& Antaramian, S. P. (2016). The role of life satisfaction in predicting student engagement and achievement. Journal of Happiness Studies, 17(4), 1681-1701. https://doi.org/10.1007/s10902-015-96651.

Huebner, E. S., Gilman, R., \& Ma, C. (2012). Perceived quality of life of children and youth. In K. C. Land, A. C. Michalos, \& M. J. Sirgy (Eds.), Handbook of social indicators and quality of life research (pp. 355372). Dordrecht: Springer.

Huebner, E. S., Hills, K. J., Siddall, J., \& Gilman, R. (2014). Life satisfaction and schooling. In M. J. Furlong, R. Gilman, \& E. S. Huebner (Eds.), Handbook of positive psychology in schools (pp. 192-207). New York: Routledge.

Huppert, F. A. (2009). Psychological well-being: Evidence regarding its causes and consequences. Applied Psychology. Health and Well-Being, 1(2), 137-164. https://doi.org/10.1111/j.1758-0854.2009.01008.x.

Kline, R. B. (2015). Principles and practice of structural equation modeling (4th ed.). New York: The Guilford Press.

Ko, C. H., Wang, P. W., Liu, T. L., Yen, C. F., Chen, C. S., \& Yen, J. Y. (2015). Bidirectional associations between family factors and internet addiction among adolescents in a prospective investigation. Psychiatry and Clinical Neurosciences, 69(4), 192-200. https://doi.org/10.1111/pcn.12204.

Lachmann, B., Sariyska, R., Kannen, C., Cooper, A., \& Montag, C. (2016). Life satisfaction and problematic internet use: Evidence for gender specific effects. Psychiatry Research, 238, 363-367. https://doi. org/10.1016/j.psychres.2016.02.017.

Lerner, J. V., Bowers, E., Minor, K., Boyd, M., Mueller, M., Schmid, K., et al. (2013). Positive youth development: Processes, philosophies, and programs. In R. M. Lerner, M. A. Easterbrooks, \& J. Mistry (Eds.), Comprehensive handbook of psychology (Vol. 6, pp. 365-392). New York: Wiley.

Leung, J. T. Y., \& Shek, D. T. L. (2019). Parental control and adolescent wellbeing in Chinese adolescents in Hong Kong. Child Indicators Research, 1-25. https://doi.org/10.1007/s12187-019-09642-6.

Lyons, M. D., Huebner, E. S., Hills, K. J., \& Van Horn, M. L. (2013). Mechanisms of change in adolescent life satisfaction: A longitudinal analysis. Journal of School Psychology, 51(5), 587-598. https://doi. org/10.1016/j.jsp.2013.07.001.

Lyons, M. D., Otis, K. L., Huebner, E. S., \& Hills, K. J. (2014). Life satisfaction and maladaptive behaviors in early adolescents. School Psychology Quarterly, 29(4), 553-566. https://doi.org/10.1037/spq0000061.

Marques, S. C., Lopez, S. J., Fontaine, A. M., Coimbra, S., \& Mitchell, J. (2015). How much hope is enough? Levels of hope and students' psychological and school functioning. Psychology in the Schools, 52(4), 325-334. https://doi.org/10.1002/pits.21833.

Massarwi, A. A., Khoury-Kassabri, M., \& Eseed, R. (2019). The correlation between delinquent peers and perpetration of serious physical violence: Religiosity as a protective factor. Child Indicators Research, 12, 2051-2065. https://doi.org/10.1007/s12187-019-9627-y.

McKinney, C., \& Renk, K. (2008). Differential parenting between mothers and fathers: Implications for late adolescents. Journal of Family Issues, 29(6), 806-827. https://doi.org/10.1177/0192513X07311222.

Park, N. (2005). Life satisfaction among Korean children and youth: A developmental perspective. School Psychology International, 26(2), 209-223. https://doi.org/10.1177/0143034305052914.

Patel, V., Flisher, A. J., Hetrick, S., \& McGorry, P. (2007). Mental health of young people: A global publichealth challenge. The Lancet, 369(9569), 1302-1313. https://doi.org/10.1016/S0140-6736(07)60368-7.

Patterson, G. R. (1982). Coercive family process. Eugene, OR: Castalia.

Pavot, W., \& Diener, E. (1993). The affective and cognitive context of self-reported measures of subjective well-being. Social Indicators Research, 28(1), 1-20. https://doi.org/10.1007/BF01086714.

Pinquart, M. (2017). Associations of parenting dimensions and styles with externalizing problems of children and adolescents: An updated meta-analysis. Developmental Psychology, 53(5), 873-932. https://doi. org/10.1037/dev0000295.

Preacher, K. J., \& Hayes, A. F. (2008). Asymptotic and resampling strategies for assessing and comparing indirect effects in multiple mediator models. Behavior Research Methods, 40(3), 879-891. https://doi. org/10.3758/BRM.40.3.879.

Proctor, C. L., Linley, P. A., \& Maltby, J. (2009). Youth life satisfaction: A review of the literature. Journal of Happiness Studies, 10(5), 583-630. https://doi.org/10.1007/s10902-008-9110-9. 
Raboteg-Saric, Z., \& Sakic, M. (2014). Relations of parenting styles and friendship quality to self-esteem, life satisfaction and happiness in adolescents. Applied Research in Quality of Life, 9(3), 749-765. https://doi. org/10.1007/s11482-013-9268-0.

Reid, J. B., Patterson, G. R., \& Snyder, J. (Eds.). (2002). Antisocial behavior in children and adolescents: A developmental analysis and model for intervention. Washington, DC: American Psychological Association.

Reitz, E., Deković, M., \& Meijer, A. M. (2006). Relations between parenting and externalizing and internalizing problem behaviour in early adolescence: Child behaviour as moderator and predictor. Journal of Adolescence, 29(3), 419-436. https://doi.org/10.1016/j.adolescence.2005.08.003.

Riley, T. N., Sullivan, T. N., Hinton, T. S., \& Kliewer, W. (2019). Longitudinal relations between emotional awareness and expression, emotion regulation, and peer victimization among urban adolescents. Journal of Adolescence, 72, 42-51. https://doi.org/10.1016/j.adolescence.2019.02.005.

Rogers, K. N., Buchanan, C. M., \& Winchell, M. E. (2003). Psychological control during early adolescence: Links to adjustment in differing parent/adolescent dyads. The Journal of Early Adolescence, 23(4), 349383. https://doi.org/10.1177/0272431603258344.

Schei, J., Jozefiak, T., Nøvik, T. S., Lydersen, S., \& Indredavik, M. S. (2016). The impact of coexisting emotional and conduct problems on family functioning and quality of life among adolescents with ADHD. Journal of Attention Disorders, 20(5), 424 433. https://doi.org/10.1177/1087054713507976.

Seligman, M. E. P., \& Csikszentmihalyi, M. (2014). Positive psychology: An introduction. In Flow and the foundations of positive psychology (pp. 279-298). Dordrecht: Springer.

Shek, D. T. L. (2007). A longitudinal study of perceived parental psychological control and psychological well-being in Chinese adolescents in Hong Kong. Journal of Clinical Psychology, 63(1), 1-22. https://doi. org/10.1002/jclp.20331.

Shek, D. T. L. (2014). Editorial: Applied research in quality of life (ARQOL): Where are we and issues for consideration. Applied Research in Quality of Life, 9(3), 465-468. https://doi.org/10.1007/s11482-0149340-4.

Shek, D. T. L. (2019). Impact of the project PATHS in Hong Kong and China. Neuropsychiatry (London), 9(1), 2217-2219. https://doi.org/10.4172/Neuropsychiatry.1000566.

Shek, D. T. L., \& Law, M. Y. M. (2016). Dimensionality of the Chinese parent-child subsystem quality scale: Confirmatory factor analyses. International Journal of Child Health and Human Development, 9(2), 207215.

Shek, D. T. L., \& Liang, L.-Y. (2018). Psychosocial factors influencing individual well-being in Chinese adolescents in Hong Kong: A six-year longitudinal study. Applied Research in Quality of Life, 13(3), 561-584. https://doi.org/10.1007/s11482-017-9545-4.

Shek, D. T. L., \& Lin, L. (2016). What predicts adolescent delinquent behavior in Hong Kong? A longitudinal study of personal and family factors. Social Indicators Research, 129(3), 1291-1318. https://doi. org/10.1007/s11205-015-1170-8.

Shek, D. T. L., \& Siu, A. M. H. (2019). "UNHAPPY” environment for adolescent development in Hong Kong. Journal of Adolescent Health, 64(6), S1-S4. https://doi.org/10.1016/j.jadohealth.2019.01.007.

Shek, D. T. L., Yu, L., Wu, F. K. Y., Zhu, X., \& Chan, K. H. Y. (2017). A 4-year longitudinal study of wellbeing of Chinese university students in Hong Kong. Applied Research in Quality of Life, 12(4), 867-884. https://doi.org/10.1007/s11482-016-9493-4.

Shek, D. T. L., \& Zhu, X. (2019). Paternal and maternal influence on delinquency among early adolescents in Hong Kong. International Journal of Environmental Research and Public Health, 16(8), 1338. https://doi.org/10.3390/ijerph16081338.

Shek, D. T. L., Zhu, X., \& Dou, D. (2019). Influence of family processes on internet addiction among late adolescents in Hong Kong. Frontiers in Psychiatry, 10, article 113. https://doi.org/10.3389 /fpsyt.2019.00113.

Shek, D. T. L., Zhu, X., \& Ma, C. M. S. (2018). The influence of parental control and parent-child relational qualities on adolescent internet addiction: A 3-year longitudinal study in Hong Kong. Frontiers in Psychology, 9, article 642. https://doi.org/10.3389/fpsyg.2018.00642.

Steinberg, L. (2001). We know some things: Parent-adolescent relationships in retrospect and prospect. Journal of Research on Adolescence, 11(1), 1-19. https://doi.org/10.1111/1532-7795.00001.

Suldo, S. M., Shaffer, E. J., \& Riley, K. N. (2008). A social-cognitive-behavioral model of academic predictors of adolescents' life satisfaction. School Psychology Quarterly, 23(1), 56-69. https://doi.org/10.1037/10453830.23.1.56.

Sun, R. C. F., \& Shek, D. T. L. (2010). Life satisfaction, positive youth development, and problem behaviour among Chinese adolescents in Hong Kong. Social Indicators Research, 95(3), 455-474. https://doi. org/10.1007/s11205-009-9531-9. 
Sun, R. C. F., \& Shek, D. T. L. (2013). Longitudinal influences of positive youth development and life satisfaction on problem behaviour among adolescents in Hong Kong. Social Indicators Research, 114(3), 1171-1197. https://doi.org/10.1007/s11205-012-0196-4.

Tarka, P. (2018). An overview of structural equation modeling: Its beginnings, historical development, usefulness and controversies in the social sciences. Quality \& Quantity, 52(1), 313-354. https://oi. org/10.1007/s11135-017-0469-8.

van der Kaap-Deeder, J., Vansteenkiste, M., Soenens, B., \& Mabbe, E. (2017). Children's daily well-being: The role of mothers', teachers', and siblings' autonomy support and psychological control. Developmental Psychology, 53(2), 237-251. https://doi.org/10.1037/dev0000218.

Wang, B., Stanton, B., Li, X., Cottrell, L., Deveaux, L., \& Kaljee, L. (2013). The influence of parental monitoring and parent-adolescent communication on Bahamian adolescent risk involvement: A threeyear longitudinal examination. Social Science and Medicine, 97, 161-169. https://doi.org/10.1016/j. socscimed.2013.08.013.

Wertz, J., Nottingham, K., Agnew-Blais, J., Matthews, T., Pariante, C. M., Moffitt, T. E., \& Arseneault, L. (2016). Parental monitoring and knowledge: Testing bidirectional associations with youths' antisocial behavior. Development and Psychopathology, 28(3), 623-638. https://doi.org/10.1017 /S0954579416000213.

Williams, L. R., \& Steinberg, L. (2011). Reciprocal relations between parenting and adjustment in a sample of juvenile offenders. Child Development, 82(2), 633-645. https://doi.org/10.1111/j.1467-8624.2010.01523. $\mathrm{x}$.

Publisher's Note Springer Nature remains neutral with regard to jurisdictional claims in published maps and institutional affiliations. 